\title{
Energy balance at the soil atmospheric interface
}

1 Majid Sedighi BSc, MSc, PhD

Lecturer, School of Mechanical, Aerospace and Civil Engineering, Faculty of Engineering, The University of Manchester, Manchester, UK (corresponding author: majid.sedighi@manchester.ac.uk)

2 Benjamin D. P. Hepburn MEng, PhD

Research Student, Geoenvironmental Research Centre, School of Engineering, Cardiff University, Cardiff, UK
3 Hywel R. Thomas FREng, FRS, FLSW, MAE

Professor and Director, Geoenvironmental Research Centre, School of Engineering, Cardiff University, Cardiff, UK

4 Philip J. Vardon MEng, PhD

Assistant Professor, Section of Geo-engineering, Delft University of Technology, Delft, the Netherlands
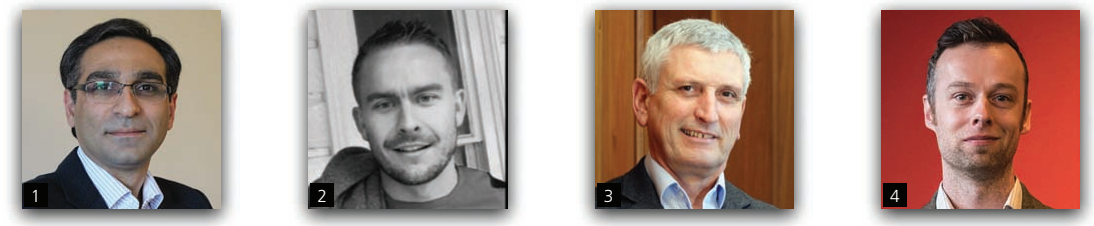

Soil atmospheric interactions play an important role within the thermal energy balance and seasonal temperature variations of the ground. This paper presents a formulation for the surface boundary conditions related to interactions between soil and atmosphere. The boundary condition formulated considers heat flow at the soil-atmosphere interface through mechanisms of shortwave radiation, long-wave radiation, sensible radiation and latent heat radiation. The effects of surface moisture flux on energy balance at the interface are explicitly included in the formulation. The developed boundary condition has been implemented in a numerical model for coupled thermal, hydraulic and mechanical behaviour of unsaturated soils. The evaporation component of the model is tested, and the results are compared with data from an experimental study at the surface of an area of agricultural land reported in the literature. The results of modelling have been found to compare favourably with the reported data set. The formulation developed for the soil atmospheric boundary condition allows climatic variables, including solar radiation, ambient air temperature, relative humidity, wind speed, rainfall and evaporation, to be incorporated in the long-term analysis of energy balance. This also enables a further detailed inspection of the climate's role in ground thermal behaviour of ground source heat systems.

\section{Notation}

A sum of the heat convection components

$A_{0} \quad$ annual amplitude of the surface soil temperature

$C_{\text {cloud }} \quad$ fractional cloud cover coefficient

$C_{\mathrm{p}} \quad$ specific heat capacity of the ground

$D_{\mathrm{h}} \quad$ thermal diffusivity

d damping depth

E evaporation flux

$E_{\mathrm{a}} \quad$ actual evaporation flux

$H$ total radiation heat flux absorbed or emitted at the soil surface

$H_{\mathrm{SW}}^{\text {Absorbed }}$ adsorbed shortwave radiation flux

$H_{\mathrm{LW}}^{\mathrm{Em}}$ rtted radiation flux emitted from the ground surface

$H_{\mathrm{LW}}^{\mathrm{Net}} \quad$ net long-wave radiation flux

$H_{\mathrm{c}} \quad$ heat storage capacity

$H_{\text {LE }} \quad$ latent heat flux

$H_{\text {SN }} \quad$ sensible heat flux

$h \quad$ relative humidity of the ground

$h_{\text {air }} \quad$ air relative humidity at the ground surface

$k \quad$ von Karman constant
$L \quad$ latent heat of vaporisation

$P \quad$ precipitation mass flux

$Q_{\mathrm{m}} \quad$ net mass flux at the ground surface

$q \quad$ specific humidity of soil

$q_{\text {air }} \quad$ specific humidity of air

$R \quad$ run-off

$r_{\text {a }} \quad$ aerodynamic resistance

$T \quad$ absolute temperature of soil

$T(z, t) \quad$ soil temperature at time $t$ and depth $z$

$T_{\mathrm{a}} \quad$ constant ground temperature

$T_{\text {air }} \quad$ absolute temperature of the air adjacent to the ground surface

$T_{\mathrm{r}} \quad$ reference temperature

$t$ time

$t_{0} \quad$ lag time from arbitrary start date to the occurrence of the minimum soil temperature in a year

$u_{\mathrm{z}} \quad$ wind speed at the reference elevation

$v_{\mathrm{a}} \quad$ velocity of air

$v_{1} \quad$ velocity of liquid

$v_{\mathrm{v}} \quad$ velocity of vapour 
depth beneath the ground surface surface roughness

incremental volume of the soil

long-wave emissivity of the air at ground level long-wave emissivity

shortwave reflection factor associated with the ground surface type

thermal conductivity

air density

density of liquid water

density of water vapour

Stefan-Boltzmann constant

$2 \pi / 365$

gradient operator

\section{Introduction}

Ground source heat pump (GSHP) systems are among the lowentropy geothermal energy extraction methods which allow energy extraction from the shallow depth of the Earth's crust in order to provide space heating and/or cooling (Sanner et al., 2003). The ground temperature at shallow depths is predominantly a function of the upper surface processes - that is, climatic conditions such as solar radiation and ambient air temperature. At greater depths, temperature increases with depth according to the geothermal gradient that is determined by the vertical heat flow in the Earth and the thermal properties of local geology (e.g. Busby et al., 2011). The ground located in closest proximity to the surface is subject to the greatest changes due to climatic variations and atmospheric conditions. Depending on the local climate and ground conditions, the annual temperature variations can typically occur within only the upper $10 \mathrm{~m}$ of ground depth (e.g. Busby et al., 2011). Beyond this depth, there are limited ground temperature variations within the shallow geothermal region.

Within the scope of closed-loop ground source heat systems, various configurations exist which can be employed to exchange heat with the ground. The ground-loop types can be broadly split into two categories according to their orientation, namely vertical and horizontal ground loops. Vertical systems are conventionally installed within boreholes with depths typically ranging between 20 and $200 \mathrm{~m}$ (Yang et al., 2010). Horizontal systems, on the other hand, typically range in depth between 1 and $2 \mathrm{~m}$ (Wu et al., 2010). Figure 1 presents a schematic diagram of a horizontal ground source heat system where the buried ground loop is shown in the cutaway section.

Analysis of GSHP systems requires consideration of two boundary conditions including: $(a)$ the ground surface boundary and (b) ground-loop boundary. The ground surface boundary represents the heat and mass exchange at the soil atmospheric interface. The ground-loop boundary represents the ground interaction with the buried ground-loop pipe surface where the heat is exchanged with the ground by way of the heat pump system. Figure 2 presents a schematic diagram of the boundary conditions of a horizontal ground source heat system.

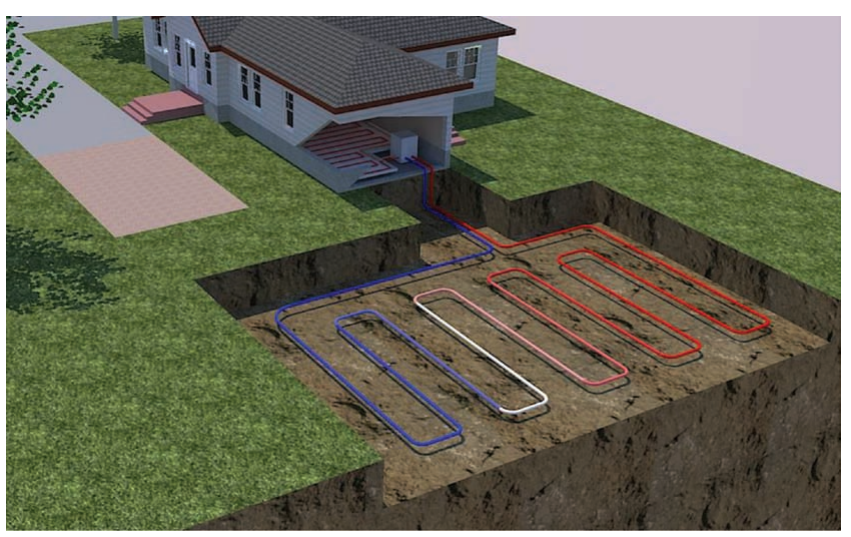

Figure 1. Schematic diagram of a horizontal ground source heat system

The proximity of horizontal ground loops to the ground surface positions this type of system within a ground depth that is subjected to annual temperature variations (Leong et al., 1998). The ground thermal behaviour is a function of the thermal energy extracted from/injected into the ground, climatic and surface conditions and ground properties. The interactions between the ground and the atmosphere can play an important role in the surface energy balance and can affect the seasonal ground temperature variations (Deardorff, 1978). This can affect thermal, hydraulic and mechanical behaviour in various ways (e.g. Vardon, 2015). The seasonal ground temperature variations with depth have been extensively studied (e.g. De Vries and Van Wijk, 1966). It has been shown that the thermal behaviour of the ground and interactions with the atmosphere can be influenced by the ground surface vegetation coverage (Gonzalez et al., 2012).

A number of investigations into the ground thermal behaviour of GSHP systems have been reported for a range of ground conditions - for example arid ground in Asia (Esen et al., 2007), North America (Mei, 1986) and the UK (Wu et al., 2011). Wu et al. (2011) presented a study on thermal performance of a horizontal system and ground temperature distributions considering fixed ambient air temperatures and fixed wind speeds. It was reported that an intermittent cycle has led to a reduced system performance for all ambient air temperature and wind speed cases. Esen et al. (2007) studied the efficiency of a horizontal ground source heat system in Turkey during the cooling mode operation (i.e. storing heat in the ground) which was located at $2 \mathrm{~m}$ depth. By using an analytical model, it was shown that the efficiency of the system under cooling mode had decreased from 56 to $46 \%$ when the ambient air temperature increased from 0 to $25^{\circ} \mathrm{C}$. The majority of investigations reported have considered a simplified form of the description of the energy balance at the ground surface (i.e. as a fixed temperature boundary condition based on annual ambient air temperature variations). An extensive experimental investigation of a horizontal ground source heat system and ground temperature 


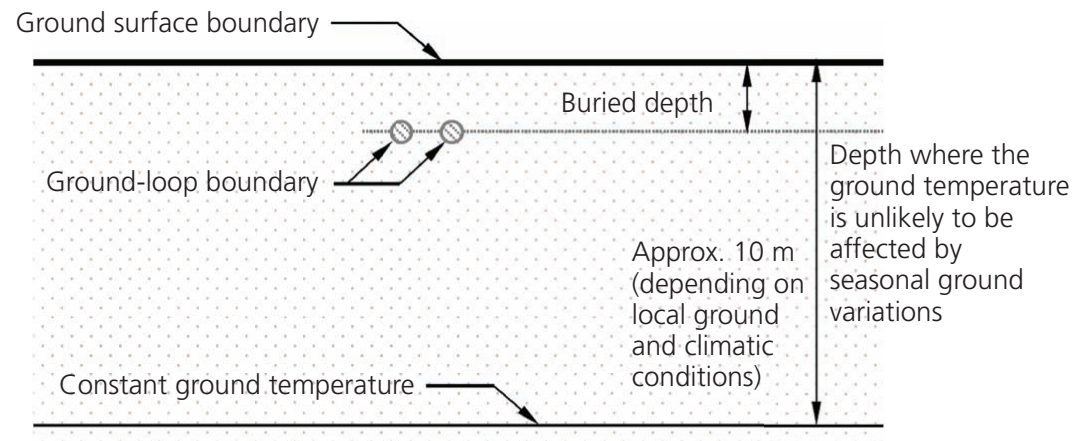

Figure 2. Schematic diagram of the ground surface boundary and ground-loop boundary in a horizontal ground source heat system

response has also been presented by Thomas et al. (2013), Hepburn (2014) and Hepburn et al. (2016). This investigation presents the soil thermal response in relation to seasonal variations and heat extraction.

The so-called energy balance equation has been reported to provide a prediction of annual and diurnal variations in ground temperature (Deardorff, 1978). The energy balance equation essentially calculates the overall radiant energy being absorbed or emitted by the thin upper layer of the ground surface. This paper revisits the energy balance at the ground atmospheric interface with the aim to provide a comprehensive description of the ground boundary condition for ground source heat system studies. A formulation for the surface boundary conditions related to thermal and hydraulic interactions between soil and atmosphere is presented in this paper. The boundary condition developed considers the heat flow at the interface between soil and atmosphere through the mechanisms of shortwave radiation, longwave radiation, sensible radiation and latent heat radiation. In addition, the effects of surface moisture flux on energy balance at the interface are explicitly considered in the coupled formulation proposed. The developed boundary condition has been implemented in a numerical model for coupled thermal, hydraulic and mechanical behaviour of unsaturated soils (e.g. Thomas and He, 1995). The accuracy of the surface boundary condition and the implementation of the model are tested against a series of experimental data.

\section{Energy balance at the soil atmospheric interface}

The surface boundary condition presented here considers the heat and moisture flow at the soil atmospheric interface. The energy balance equation is used to provide a description of the annual and diurnal ground temperature variations (Deardorff, 1978). Four major mechanisms of heat exchange between the ground surface and atmosphere are considered, given as (van Wijk, 1966)

- shortwave heat radiation

- long-wave heat radiation

- sensible heat radiation

- latent heat radiation.

Figure 3 presents a schematic diagram of the heat exchange mechanisms considered at the soil-atmosphere interface.

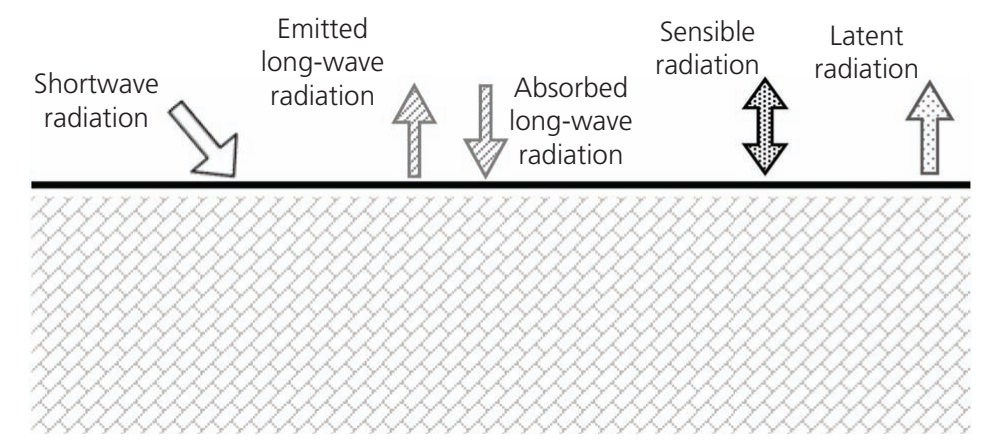

Figure 3. Major mechanisms of energy exchange at the soil-atmosphere interface 
A general form of the energy balance equation can be presented as (van Wijk, 1966)

1. $H=H_{\mathrm{SW}}^{\mathrm{Absorbed}}-\left(H_{\mathrm{LW}}^{\mathrm{Net}}+H_{\mathrm{SN}}+H_{\mathrm{LE}}\right)$

where $H$ is the total radiation heat flux absorbed or emitted at the soil surface. $H_{\mathrm{SW}}^{\mathrm{Abs} o r b e d}$ is the adsorbed shortwave radiation flux, $H_{\mathrm{LW}}^{\mathrm{Net}}$ is the net long-wave radiation flux, $H_{\mathrm{SN}}$ represents the sensible heat flux and $H_{\mathrm{LE}}$ is the latent heat flux. It is noted that the unit of heat flux used is watts per square metre.

The following sections provide the details of the individual components of the surface energy balance equation described in Equation 1.

\section{Shortwave radiation}

Shortwave radiation is a combination of direct and diffused solar radiation striking the Earth's surface. The diffuse radiation is primarily caused by clouds, dust and molecules scattering in the atmosphere (van Wijk and Scholte Ubing, 1966). This is commonly referred to as shortwave radiation, as the majority of the associated radiation has wavelengths within the infrared and visible bands of the electromagnetic spectrum (van Wijk and Scholte Ubing, 1966). The total shortwave flux striking the Earth's surface varies on a diurnal and annual basis, depending on the solar inclination and climatic conditions. A considerable fraction of the shortwave flux that reaches the Earth's surface is reflected. The exact proportion of the radiation reflected depends on the ground surface coverage and reflection properties. The fraction of the shortwave radiation flux absorbed at the surface can be presented as (Deardorff, 1978)

\section{2. $H_{\mathrm{SW}}^{\mathrm{Absorbed}}=\varepsilon_{\mathrm{SW}} H_{\mathrm{SW}}$}

where $H_{\mathrm{SW}}^{\mathrm{Abs}}$ irbed is the heat flux associated with the absorbed shortwave radiation and $\varepsilon_{S \mathrm{~W}}$ is the shortwave reflection factor associated with the ground surface type.

In order to calculate the shortwave radiation component, a representative value of shortwave radiation is required. Values either can be obtained by way of monitoring, using appropriate historical records, or can be approximated using irradiance models. A number of theoretical and empirical irradiance models have also been proposed (e.g. van Wijk and Scholte Ubing, 1966; Woodward et al., 2001). The shortwave reflection factor varies for different surfaces and recommended values have been provided in the literature (e.g. van Wijk and Scholte Ubing, 1966).

\section{Net long-wave radiation}

The net long-wave radiation at the ground surface can be described as a combination of long-wave radiation being emitted from the ground and long-wave radiation being absorbed from the atmosphere. Within the context of this formulation, the absorbed radiation is referred to as the long-wave radiation passing from the atmosphere towards the Earth's surface, with the emitted radiation travelling in the opposite direction. This can be expressed as

3. $H_{\mathrm{LW}}^{\mathrm{Net}}=H_{\mathrm{SW}}^{\mathrm{Absorbed}}-H_{\mathrm{LW}}^{\mathrm{Emitted}}$

where $H_{\mathrm{SW}}^{\mathrm{Abs} o r b e d}$ is the radiation flux absorbed at the ground surface and $H_{\mathrm{LW}}^{\text {Emitted }}$ is the radiation flux emitted from the ground surface.

The amount of long-wave radiation absorbed from the atmosphere is dependent on cloud formation. The proposed approaches commonly incorporate coefficients which are specific to local regions. A general approach was formulated by Imberger and Patterson (1981) to calculate the long-wave radiation being absorbed at the ground surface from the atmosphere, given as

4. $H_{\mathrm{SW}}^{\mathrm{Absorbed}}=\varepsilon_{\mathrm{LW}}^{A} \sigma T_{\text {air }}^{4}\left(1+0 \cdot 17 C_{\text {cloud }}^{2}\right)$

where $\varepsilon_{\mathrm{LW}}^{A}$ is the long-wave emissivity of the air at ground level (non-dimensional), $C_{\text {cloud }}$ is the fractional cloud cover coefficient ( $C_{\text {cloud }}=0$ for clear sky and $C_{\text {cloud }}=1$ for totally overcast) and $T_{\text {air }}$ is the absolute temperature of the air adjacent to the ground surface.

The long-wave radiation being emitted by a body can be calculated using Stefan-Boltzmann's law (Woodward et al., 2001). The Stefan-Boltzmann law states that the energy emitted by a body is directly proportional to the fourth power of its absolute temperature, given as (Lewis et al., 2004)

5. $H_{\mathrm{LW}}^{\mathrm{Emitted}}=\varepsilon_{\mathrm{LW}} \sigma T^{4}$

where $\varepsilon_{\mathrm{LW}}$ is the long-wave emissivity of the body (dimensionless) and $\sigma$ is the Stefan-Boltzmann constant $(5.67 \times$ $\left.10^{-8} \mathrm{~W} /\left(\mathrm{m}^{2} \mathrm{~K}^{4}\right)\right) . T$ represents the absolute temperature.

\section{Sensible heat radiation}

Sensible heat radiation can be defined as the heat exchange within a thermodynamic system that has a sole effect of temperature variation on the constituent bodies (i.e. not energy associated with a phase change). Sensible heat radiation is a function of both thermal conduction and convection. With respect to the ground surface boundary, the sensible heat flux is (Deardorff, 1978)

6. $H_{\mathrm{SN}}=\frac{\rho_{\mathrm{a}} C_{\mathrm{p}}}{r_{\mathrm{a}}}\left(T-T_{\text {air }}\right)$ 
Energy balance at the soil atmospheric

interface

Sedighi, Hepburn, Thomas and Vardon where $\rho_{\mathrm{a}}$ is the air density $\left(\mathrm{kg} / \mathrm{m}^{3}\right), C_{\mathrm{p}}$ is the ground specific heat capacity $(\mathrm{J} /(\mathrm{kg} \mathrm{K}))$ and $r_{\mathrm{a}}$ is the aerodynamic resistance.

The aerodynamic resistance accounts for the mixing and turbulence of the air above the evaporating surface (Fuchs and Tanner, 1967). For the formulation of the surface boundary condition presented here, the following transition function proposed by Sverdrup (1946) is applied

7. $r_{\mathrm{a}}=\frac{k^{2} u_{\mathrm{z}}}{\left[\ln \left(z / z_{0}\right)\right]^{2}}$

where $k$ is the von Karman constant (equal to $0 \cdot 41$ ) and $u_{\mathrm{z}}$ is the wind speed at the reference elevation. $z_{0}$ is the surface roughness, which allows the surface texture (e.g. grass and concrete) to be considered when calculating the mixing characteristics of the air immediately above the ground surface. When considering the effect of the surface boundary, this feature can be important in the recharge of the ground.

The relationship presented in Equation 6 is essentially a form of Fourier's law of conduction, which forms the foundation of onedimensional heat conduction (Deardorff, 1978). The components of $\rho_{\mathrm{a}}, C_{\mathrm{p}}$ and $r_{\mathrm{a}}$ provide a modified thermal conductivity value, thereby incorporating a convective component within the equation (Deardorff, 1978).

\section{Latent heat radiation}

Latent heat radiation can be defined as the absorption or release of energy within a thermodynamic system that occurs without a change in temperature (i.e. energy related to molecule changes of state). In the context of the surface boundary condition, this is primarily linked to the evaporation of water from the upper regions of the ground surface.

The latent heat flux due to evaporation is calculated as follows

\section{8. $H_{\mathrm{LE}}=L E$}

where $L$ is the latent heat of vaporisation $(\mathrm{kJ} / \mathrm{kg})$ and $E$ is evaporation flux.

The water vapour flux presented in Equation 7 is the moisture flux at the ground surface, which represents the evaporation from the soil surface. The evaporation process is affected and controlled by atmospheric, surface and ground factors (Deardorff, 1978; Fuchs and Tanner, 1967). The rate of evaporation is greatly influenced by the moisture content of soil at the ground surface, linking the boundary to the moisture transfer in the soil. Based on the calculations of Dalton's mass transfer formula, the evaporation rate can be given as (Deardorff, 1978)

9. $E=\rho_{\mathrm{a}} r_{\mathrm{a}}\left(q-q_{\text {air }}\right)$ where $q$ is the specific humidity of the soil (mass of water vapour in a unit mass of moist air) at the ground surface and $q_{\text {air }}$ is the specific humidity of air.

Equation 9, with substitution of Equation 6 and energy balance (without shortwave and long-wave radiation) can yield the Penman-Monteith equation (Monteith, 1965) that includes the effects of the vegetation bulked on the aerodynamic resistance. Maintaining the separation of these terms makes easier substitution into a coupled model, with each of the boundary conditions separately addressed.

The value of the rate of evaporation $(E)$ calculated by Equation 8 is equal to the so-called potential evaporation. The term 'potential evaporation' can be described as the upper limit or the maximum rate of evaporation from a surface (Barton, 1979). With respect to the evaporation from soil, potential evaporation remains a valid approximation of the overall evaporation provided that there is a constant supply of available water at the ground surface - that is, when the ground surface is saturated (Wilson et al., 1997). As the surface of soil enters the unsaturated state, the availability of water depends on the water retention characteristics of the soil. Wilson et al. (1997) presented a modified Dalton's mass transfer equation to predict the evaporative rates from unsaturated soil surfaces

10. $E_{\mathrm{a}}=E\left(\frac{h-h_{\text {air }}}{1-h_{\text {air }}}\right)$

where $E_{\mathrm{a}}$ is the actual evaporation flux, $h$ is the relative humidity of the ground surface and $h_{\text {air }}$ is the relative humidity of air at the ground surface.

The latent heat flux due to evaporation can therefore be expanded as follows

11. $H_{\mathrm{LE}}=L \rho_{\mathrm{a}} r_{\mathrm{a}}\left(q-q_{\mathrm{air}}\right)\left(\frac{h-h_{\mathrm{air}}}{1-h_{\mathrm{air}}}\right)$

\section{Surface moisture flux}

In order to model the coupled heat and mass boundary condition, a representative mass boundary describing hydrological processes at the ground surface is presented. Assuming that the net moisture flux at the surface boundary is a function of hydrological process only, the following equation can be applied to calculate the ground surface moisture flux (Fredlund et al., 2011)

12. $Q_{\mathrm{m}}=P-E_{\mathrm{a}}-R$

where $Q_{m}$ is the net mass flux at the ground surface $\left(\mathrm{kg} / \mathrm{m}^{2}\right), P$ is the precipitation mass flux, $E_{\mathrm{a}}$ is the evaporation mass flux according to Equation 10 and $R$ is the run-off. 
For highly compressible soils, consolidation processes should also be taken into account; see for example Vardon et al. (2014). However, it would be unlikely that such soils would be selected for use for GSHP systems.

Equation 12 presents the surface moisture exchange in terms of liquid and vapour phases. Precipitation data are available for specific geographical regions; therefore, representative values can be obtained and prescribed in most cases.

\section{Numerical implementation and model development}

The surface boundary conditions described in the previous section have been implemented within an existing numerical model of coupled thermal, hydraulic and mechanical behaviour of unsaturated soils (Thomas and He, 1995). The model considers the heat and moisture flow in unsaturated soils.

The governing equation of moisture flow is based on the principle of mass conservation and follows the formulation provided by Thomas and He (1995). This can be expressed as

$$
\text { 13. } \begin{array}{r}
\frac{\partial}{\partial t}\left(\rho_{1} \theta_{1} \delta V\right)+\frac{\partial}{\partial t}\left(\rho_{\mathrm{v}} \theta_{\mathrm{a}} \delta V\right) \\
=-\delta V \nabla\left(\rho_{1} \boldsymbol{v}_{1}\right)-\delta V \nabla\left(\rho_{1} \boldsymbol{v}_{\mathrm{v}}\right)-\delta V \nabla\left(\rho_{\mathrm{v}} \boldsymbol{v}_{\mathrm{a}}\right)
\end{array}
$$

where $t$ is time (s), $\rho_{1}$ is the density of liquid water $\left(\mathrm{kg} / \mathrm{m}^{3}\right), \theta_{1}$ is the volumetric water content, $\rho_{\mathrm{v}}$ is the density of water vapour $\left(\mathrm{kg} / \mathrm{m}^{3}\right)$ and $\theta_{\mathrm{a}}$ is the volumetric air content. $\nabla$ is the gradient operator, and $\delta V$ is the incremental volume of the soil. $v_{1}$ is the velocity of liquid $(\mathrm{m} / \mathrm{s}), \boldsymbol{v}_{\mathrm{v}}$ is the velocity of vapour $(\mathrm{m} / \mathrm{s})$ and $\boldsymbol{v}_{\mathrm{a}}$ is the velocity of air $(\mathrm{m} / \mathrm{s})$

The governing equation of heat transfer is based on the energy conservation law in unsaturated porous media (Thomas and $\mathrm{He}$, 1995). Based on the formulation presented Thomas and $\mathrm{He}$ (1995), the governing equation of heat transfer can be presented as

$$
\frac{\partial}{\partial t}\left[H_{\mathrm{c}}\left(T-T_{\mathrm{r}}\right)\right]=-\delta V \nabla\left[-\lambda_{\mathrm{T}} \nabla T+A\left(T-T_{\mathrm{r}}\right)\right.
$$

$$
\left.+L\left(\rho_{1} v_{v}+\rho_{\mathrm{v}} v_{\mathrm{a}}\right)\right]
$$

where $H_{\mathrm{c}}$ is the heat storage capacity $(\mathrm{J} / \mathrm{K}), T_{\mathrm{r}}$ stands for the reference temperature $(\mathrm{K}), \lambda_{\mathrm{T}}$ is the thermal conductivity $(\mathrm{W} /(\mathrm{m} \mathrm{K}))$ and $A$ stands for the sum of the heat convection components.

Details of the expanded governing equations for moisture and heat transfer presented in Equations 13 and 14 can be found in Thomas and He (1995).

The formulation of water flow has been implemented within an existing numerical model (Compass) developed at the
Geoenvironmental Research Centre, Cardiff University, which is based on finite-element and finite-difference methods (Sedighi et al. 2016; Thomas and He, 1995; Thomas et al., 2012). The Galerkin weighted residual method has been adopted, by which the spatial discretisation is developed and the temporal discretisation is achieved by applying an implicit finite-difference algorithm (Thomas and He, 1995). The model has been extensively tested and applied to study the coupled behaviour of unsaturated soils (e.g. Thomas et al., 2012). Details of the numerical formulation and computational aspects have been discussed in previous publications (e.g. Thomas and He, 1995); therefore, the details are not repeated here.

Implementation of the developed surface boundary formulations within the numerical model is presented here. Figure 4 shows a schematic diagram of the ground surface boundary and a model domain discretised into a number of elements. Based on the series of theoretical formulations provided in the section titled 'Energy balance at the soil atmospheric interface', the climatic variables that are required to model the surface are

ambient air temperature
solar radiation flux
relative humidity of air
wind speed
rainfall variables.

These climatic variables are commonly monitored in the field, and representative values can be obtained for most regions from metrological data. The climatic variables are prescribed in the model as time-dependent variables for the computation of the surface boundary condition. A linear interpolation is used to calculate the representative climatic variables between the timedependent values. The resolution of the prescribed data is dependent on the nature of the variables (i.e. fluctuating on an hourly or diurnal basis), the maximum simulation time step and the resolution of the original data.

The ground surface boundary is prescribed by two fluxes, one representing hydraulic surface interactions (i.e. moisture) and the other representing thermal interactions. These two fluxes are connected in two ways: $(a)$ by the coupled heat and moisture flow formulation and $(b)$ by the latent heat component of the energy balance equation. In order to calculate these fluxes in the model, a sequential algorithm was developed and implemented within the existing numerical code. The heat and moisture fluxes representing the ground surface boundary are calculated first at each time step. According to the surface boundary formulation, calculation of the fluxes requires ground surface information regarding temperature, relative humidity and degree of saturation. The ground properties previously listed are extracted at the beginning of flow analysis at each time step for each node located at the ground surface within the model domain. This allows the surface fluxes to be locally calculated on a node-by-node basis for the analysis. Further details can be found in Hepburn (2014). 


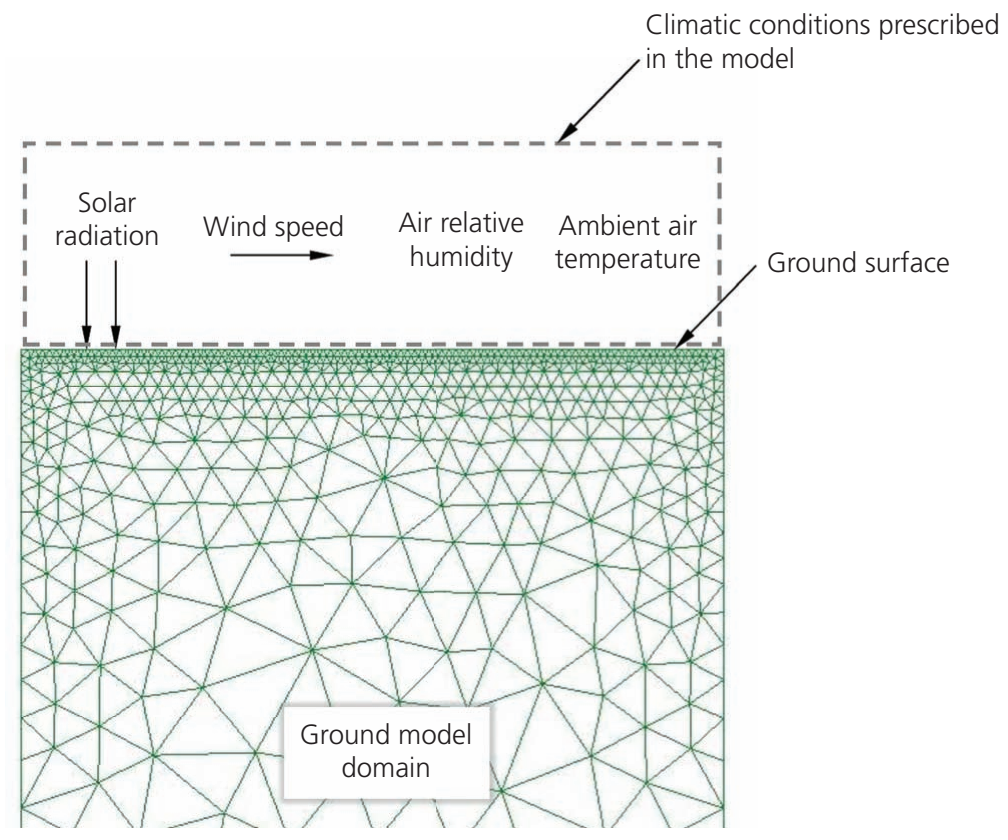

Figure 4. Schematic diagram of a ground domain showing the ground surface boundary condition and the climatic variables required in order to calculate the ground surface boundary components

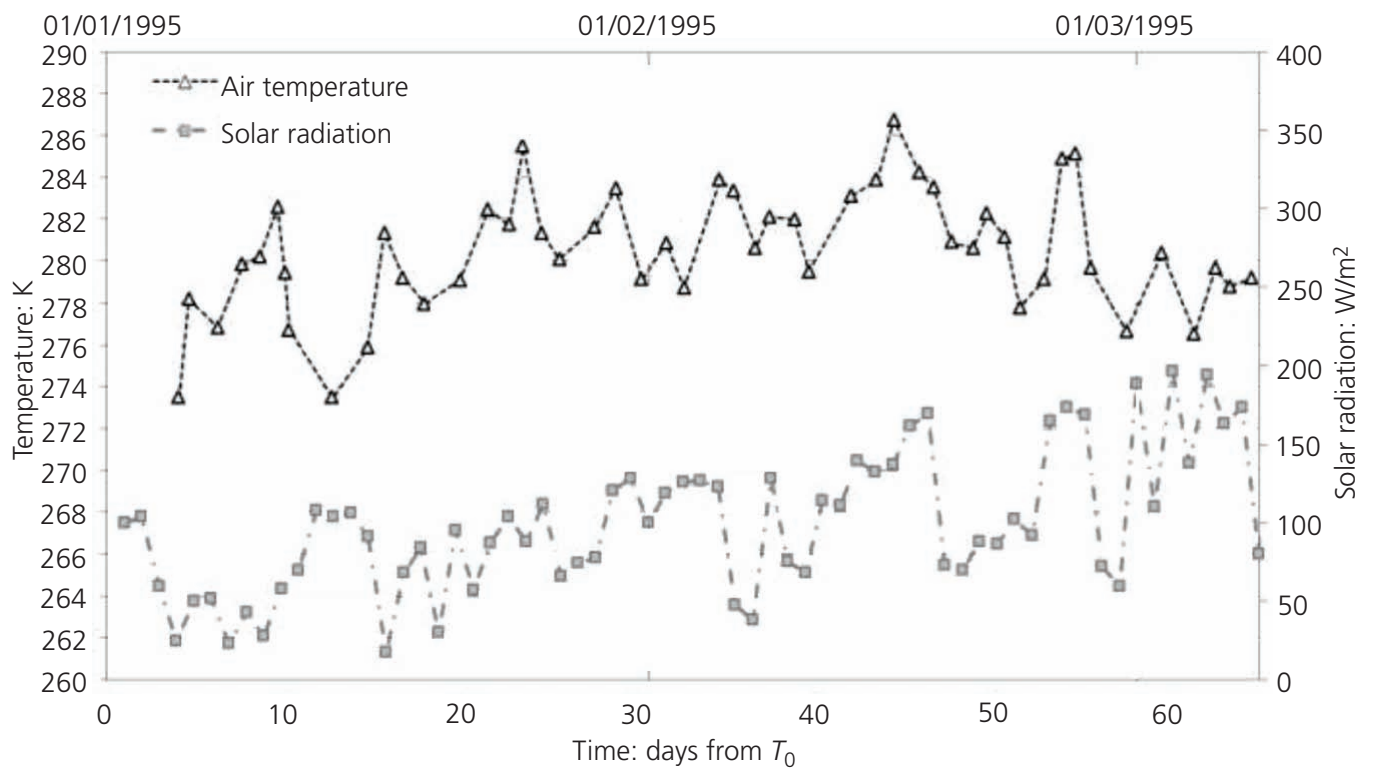

Figure 5. Daily evolution of air temperature and solar radiation recorded at the site (after Gonzalez-sosa et al., 1999) 


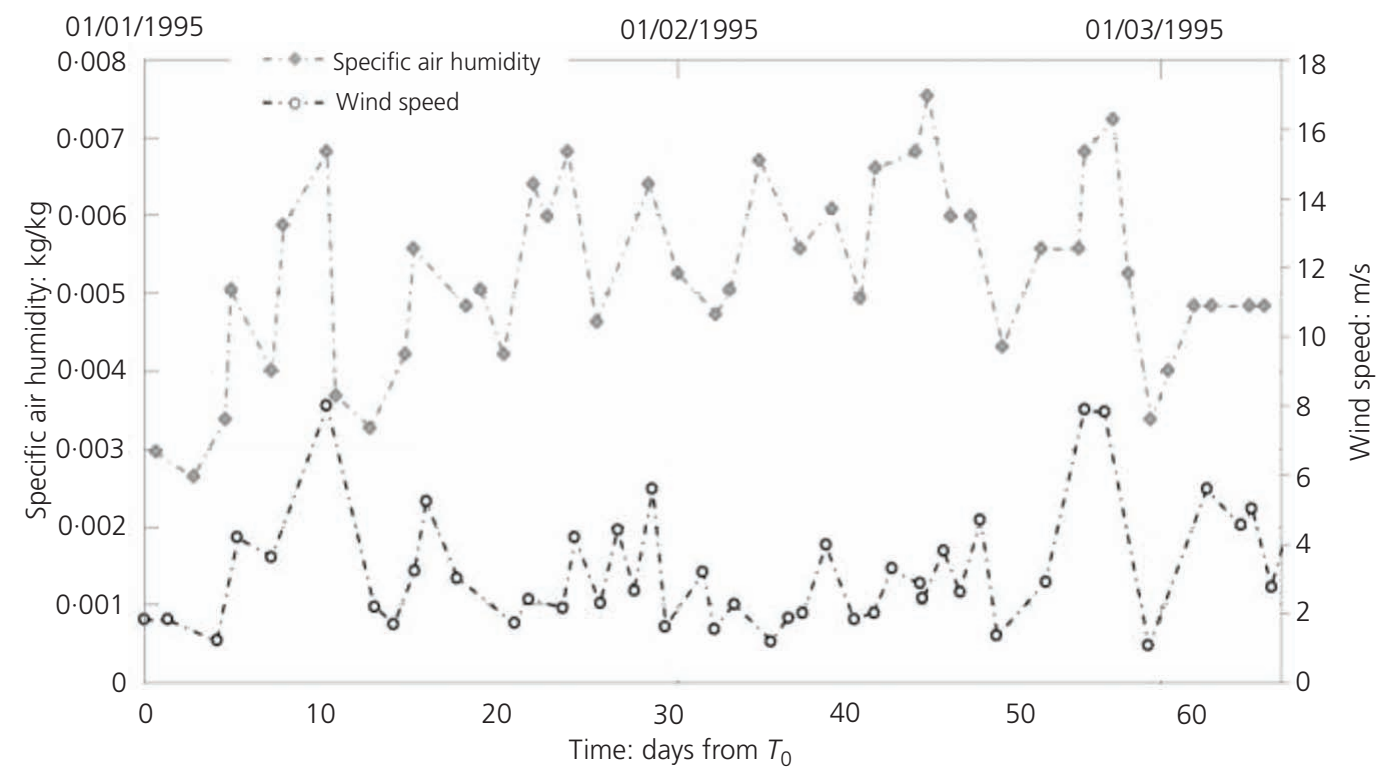

Figure 6. Daily evolution of specific air humidity and wind velocity recorded at the site (after Gonzalez-sosa et al., 1999)

\section{Model validation: evaporation at the soil atmospheric interface}

The formulation developed for the ground surface boundary was tested against the results of an experimental study presented by Gonzalez-sosa et al. (1999). The validity of the adopted formulation for evaporation is examined against data provided by Gonzalez-sosa et al. (1999), where the long-term exchange of energy and water at the surface of agricultural land in southern France has been studied. As part of the experimental investigation, sensors were installed to measure the surface water exchanges and a soil investigation was carried out to obtain the soil properties at the site (Gonzalez-sosa et al., 1999). A validation model representing the thermal and hydraulic behaviour of the ground at the site for the period of monitoring (1 January 1995-7 January 1995) was developed. The climatic data, surface hydraulic components (i.e. evaporation, precipitation and run-off) and soil properties have been used. The results of hydraulic components of the ground surface boundary condition (i.e. surface run-off and evaporation) predicted by the model are compared with experimental data presented by Gonzalez-sosa et al. (1999).

The soil at the site has been described as a 'typical hydromorphic boulbene with silt loam texture' (Gonzalez-sosa et al., 1999). The

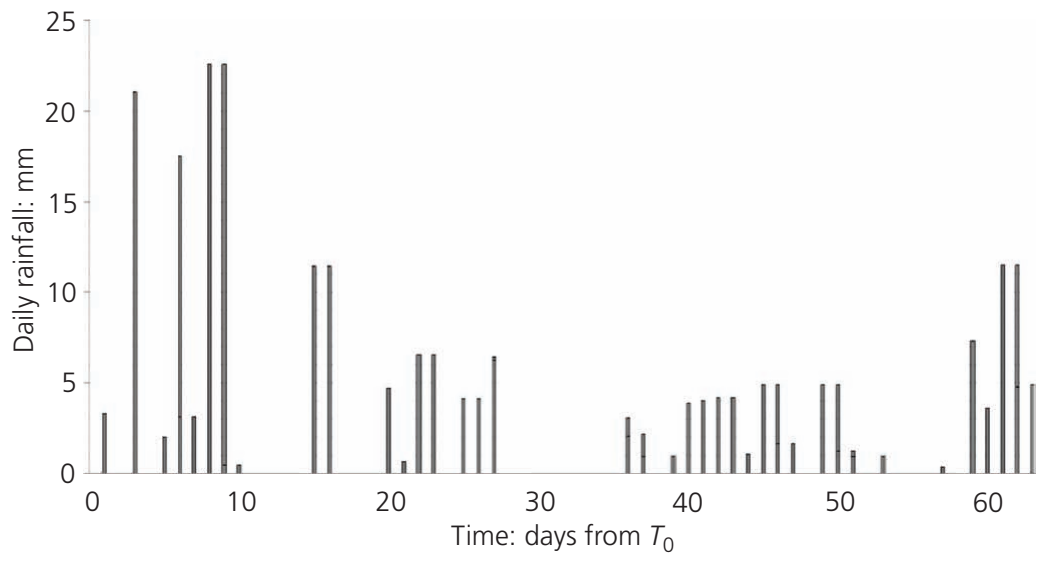

Figure 7. Daily evolution of rainfall recorded at the site (after Gonzalez-sosa et al., 1999) 
Environmental Geotechnics

Volume 5 Issue EG3
Energy balance at the soil atmospheric

interface

Sedighi, Hepburn, Thomas and Vardon soil properties presented by Gonzalez-sosa et al. (1999) were used in the simulation. The properties were presented in the form of discrete strata, the upper and lower levels. Materials were prescribed within the validation model such that they coincided with the defined strata. Beyond the depth of $1.3 \mathrm{~m}$, no material data were available; therefore, the material parameters for deepest strata reported by Gonzalez-sosa et al. (1999) have been adopted within the remainder of the model (i.e. ground ranging from $1 \cdot 3$ to $10.0 \mathrm{~m}$ deep).

An empirical relationship describing the soil thermal conductivity was used, following Gonzalez-sosa et al. (1999) for the specific soil type found at the experimental site. The initial porewater pressure values at different depths were defined by Gonzalez-sosa et al. (1999) as a function of pressure head. van Genuchten's equation was used to describe the soil water characteristic curve (van Genuchten, 1980) by using the parameters provided by Gonzalez-sosa et al. (1999). The water table was reported to be at a depth of $4 \mathrm{~m}$ below the ground surface. Initial ground temperatures were provided at depths of $0.01,0.05$ and $0.5 \mathrm{~m}$ (Gonzalez-sosa et al., 1999).

The initial ground temperature beyond a depth of $0.5 \mathrm{~m}$ was approximated using an analytical expression proposed by Hillel (1980), which provides the ground temperature profile based on soil parameters and climatic conditions, given as

15. $T(z, t)=T_{\mathrm{a}}+A_{0} \exp \left(-\frac{z}{d}\right) \sin \left[\frac{2 \pi\left(t-t_{0}\right)}{365}-\frac{z}{d}-\frac{\pi}{2}\right]$

where $T(z, t)$ is the soil temperature at time $t(\mathrm{~d})$ and depth $z$ beneath the ground surface $(\mathrm{m}), T_{\mathrm{a}}$ is the constant ground temperature $\left({ }^{\circ} \mathrm{C}\right), A_{0}$ is the annual amplitude of the surface soil temperature $\left({ }^{\circ} \mathrm{C}\right)$ and $t_{0}$ is the lag time from arbitrary start date to the occurrence of the minimum soil temperature in a year (d). $d$ is damping depth, which is calculated as

16. $d=\frac{2 D_{\mathrm{h}}}{\omega}$

where $D_{\mathrm{h}}$ is thermal diffusivity $\left(\mathrm{m}^{2} / \mathrm{s}\right)$ and $\omega$ is $2 \pi / 365\left(\mathrm{~d}^{-1}\right)$.

The values of $A_{0}$ and $t_{0}$ were provided by Calvet et al. (1999). The value of $T_{\mathrm{a}}$ is equivalent to the constant ground temperature found beyond the ground region affected by seasonal fluctuations. In the northern hemisphere, a reasonable value to assume for this is approximately $12^{\circ} \mathrm{C}$ (Busby et al., 2011).

The climatic variables of ambient air temperature, solar radiation, specific air humidity, wind speed and rainfall presented by Gonzalez-sosa et al. (1999) and prescribed in the model are shown in Figures 5-7.

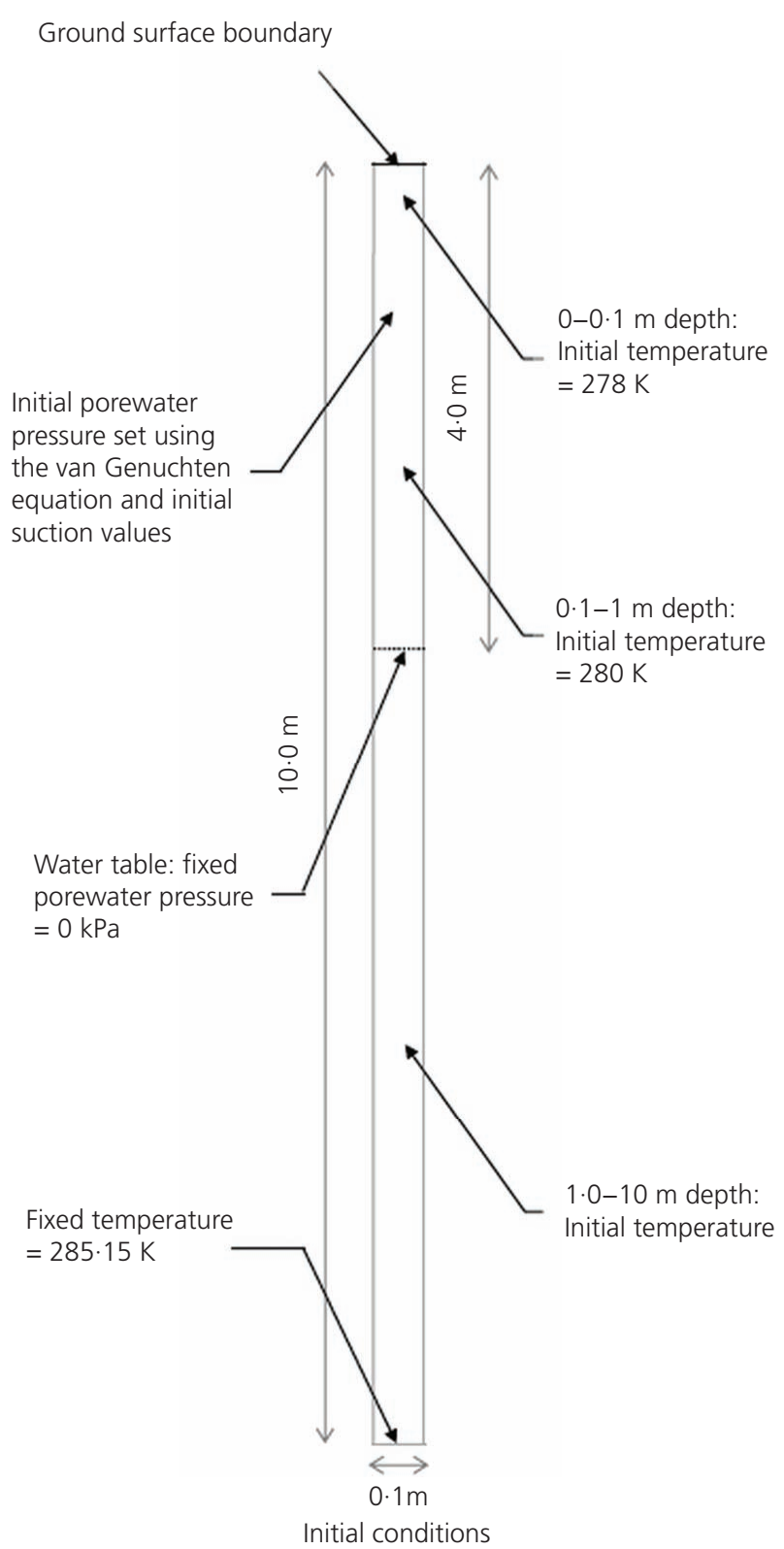

Figure 8. The initial and boundary conditions applied to the surface evaporation test

A two-dimensional (2D) simulation was carried out. The soil was assumed to be anisotropic in the vertical direction according to soil data provided. Climatic variables were assumed uniform across the whole site. The ground properties were assumed representative across the whole site. The selected domain extends downwards to a depth of $10 \mathrm{~m}$ and across to a width of $0.1 \mathrm{~m}$. The model was discretised into a mesh consisting of nonstructured and non-uniform linear triangular elements, so an upgrade to non-uniform $2 \mathrm{D}$ geometry is straightforward. A varying time-stepping algorithm was employed within the simulation. The simulation length was $5702400 \mathrm{~s}$, coinciding with the 65-d period between 1 January and 7 March 1995. 


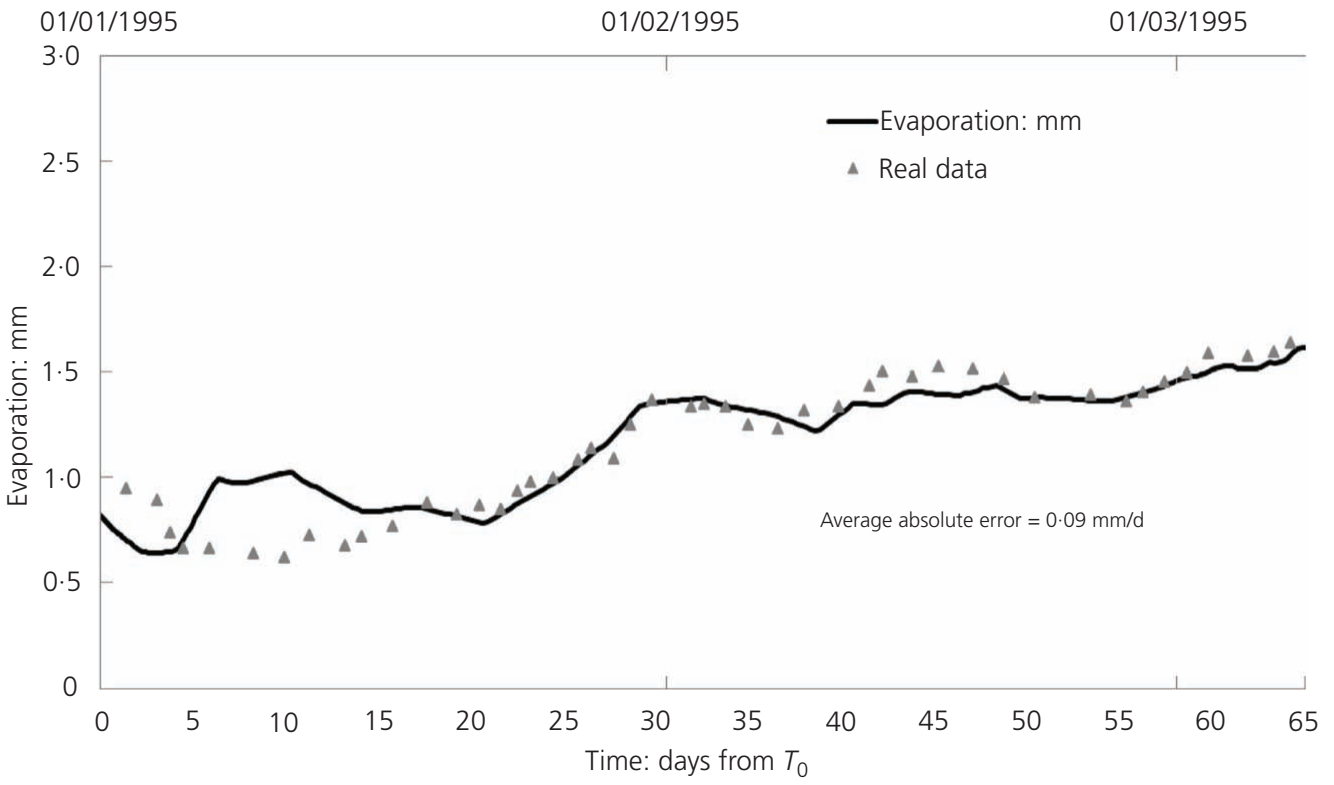

Figure 9. Results of numerical simulations and experimental data for the total daily evaporation. Experimental data were adopted from Gonzalez-sosa et al. (1999)

Figure 8 presents a schematic diagram of the initial and boundary conditions for the validation exercise.

The primary aim of this model is to validate the hydraulic component of the developed surface boundary condition. The hydraulic exchange at the ground surface can be analysed knowing the controlling parameters, namely precipitation, evaporation and run-off (Deardorff, 1978). In this case, the precipitation is a measured value prescribed within the model and therefore is known to be correct. Run-off occurs only once the upper ground surface is saturated. The experimental data reported no run-off during the period investigated; therefore, the applicability of this assumption was not tested. The evaporation component of the boundary condition implemented in the model is tested by way of comparison with field data.

The simulated evaporation and the measured evaporation based on data collected at the monitoring site can be found in Figure 9. For the purpose of this comparison, the total daily evaporation $(\mathrm{mm})$ for the simulated and measured data has been presented. From Figure 9, it can be seen that the simulated daily evaporation trends were generally in close agreement with those exhibited by the real data. It is noted that the simulated evaporation rates did differ from the experimental results between days 5 and 15. Based on the proximity of the deviations to the beginning of the simulation, it is believed that this period of deviation is due to the initial conditions assumed within the model. Over the 65-d simulation period, the average absolute error between the simulated and experimental data was $0.09 \mathrm{~mm} / \mathrm{d}$. The hydraulic component of the developed surface boundary condition was analysed in terms of the predicted run-off and evaporation. At no point during the simulation did the surface reach saturation, leading to no surface run-off, concurring with the reported experimental data. The simulated evaporation showed close agreement with the measured values over the 65 -d simulation period with the exception of one 10-d period.

\section{Conclusions}

A formulation for the heat and mass exchange at the soil atmospheric interface was presented. The surface boundary condition presented includes coupled thermo-hydraulic behaviour by considering a range of climatic variables and mechanisms. These include solar radiation, ambient air temperature, relative humidity, wind speed, rainfall and evaporation. The developed boundary condition has been implemented within a coupled thermal, hydraulic and mechanical numerical model by using a sequential approach.

The surface boundary condition was tested against a series of experimental data by which the validity of the hydraulic component of the surface boundary condition implemented was examined. The results of modelling the evaporation at the soil atmospheric interface were found to compare favourably with the reported values from the site. It is noted that only the results of testing the evaporation component of the model have been presented here. Further testing and validation exercises are therefore required to improve confidence in the developments.

The development and implementation of the boundary allows climatic variables to be included within future models for studying 
the effects of boundary condition and climatic interactions on the performance of GSHP systems. This will enable a more detailed inspection of the climate's role in the coupled thermo-hydraulic ground behaviour in response to heat extraction by way of ground source heat systems. In particular, by using the developed boundary condition, the effects of surface material properties at the soil atmospheric interface on the performance and recharge of ground source heat systems can be investigated. The developed boundary is more sophisticated than examples found in the literature, allowing consideration of not only the climatic variables but also surface material properties. The application of this boundary within a numerical model will allow a better representation of surface materials and climatic conditions.

\section{Acknowledgements}

The work described in this paper has been carried out as a part of the Geoenvironmental Research Centre's Seren project, which is funded by the Welsh European Funding Office. The financial support is gratefully acknowledged.

\section{REFERENCES}

Barton IJ (1979) A parameterisation of the evaporation from nonsaturated surfaces. Journal of Applied Meteorology 18(1): $43-47$.

Busby J, Kingdon A and Williams J (2011) The measured shallow temperature field in Britain. Quarterly Journal of Engineering Geology and Hydrogeology 44(3): 373-387, http://dx.doi.org/ 10.1144/1470-9236/10-049.

Calvet JC, Bessemoulin P, Noilhan J et al. (1999) MUREX: a landsurface field experiment to study the annual cycle of the energy and water budgets. Annales Geophysicae 17(1): 838-854, http://dx.doi.org/10.1007/s00585-999-0838-2.

De Vries DA and van Wijk WR (1966) Periodic temperature variations in a homogeneous soil. In Physics of the Plant Environment (van Wijk WR (ed.)). North Holland, Amsterdam, the Netherlands.

Deardorff JW (1978) Efficient prediction of ground surface temperature and moisture, with inclusion of a layer of vegetation. American Geophysical Union 83(4): 1889-1903, http://dx.doi.org/10.1029/JC083iC04p01889.

Esen H, Inalli M, Esen M and Pihtili K (2007) Energy and exergy analysis of a ground-coupled heat pump system with two horizontal ground heat exchangers. Building and Environment 42(1): 3606-3615, http://dx.doi.org/10.1016/j.buildenv.2006. 10.014 .

Fredlund MD, Zhang JM, Tran D and Fredlund DG (2011) Coupling heat and moisture flow for the computation of actual evaporation. Proceedings of the Canadian Geotechnical Conference and Fifth Pan-American Conference, Toronto, ON, 2-6 October, Paper No. 1058.

Fuchs M and Tanner CB (1967) Evaporation from a drying soil. Journal of Applied Meteorology 6(1): 852-857.

Gonzalez RG, Verhoef A, Vidale PL et al. (2012) Interactions between the physical soil environment and a horizontal ground coupled heat pump, for a domestic site in the UK. Renewable
Energy 44(1): 141-153, http://dx.doi.org/10.1016/j.renene. 2012.01.080.

Gonzalez-sosa E, Braud I, Jean-Louis T et al. (1999) Modelling heat and water exchanges of fallow land covered with plantresidue mulch. Agriculture and Forest Meteorology 97(1): 151-169, http://dx.doi.org/10.1016/S0168-1923(99)00081-7. Hepburn BDP (2014) An Investigation of the Behaviour of the Ground in Response to Energy Extraction. $\mathrm{PhD}$ thesis, Cardiff University, Cardiff, UK. See http://orca.cf.ac.uk/59052/ (accessed 15/08/2016).

Hepburn BDP, Sedighi M, Thomas HR and Manju (2016) Fieldscale monitoring of a horizontal ground source heat system. Geothermics 61: 86-103, http://dx.doi.org/10.1016/j. geothermics.2016.01.012.

Hillel D (1980) Applications of Soil Physics. Academic, New York, NY, USA.

Imberger J and Patterson JC (1981) A dynamic reservoir simulation model - DYRESM:5. In Transport Modes for Inland and Coastal Waters (Fischer HB (ed.)). Academic Press, San Diego, CA, USA, pp. 310-361.

Leong WH, Tarnawski VR and Aittomaki A (1998) Effect of soil type and moisture content on ground heat pump performance. International Journal of Refrigeration 21(8): 595-606, http:// dx.doi.org/10.1016/S0140-7007(98)00041-3.

Lewis RW, Nithiarasu P and Seetharamu KN (2004) Fundamentals of the Finite Element Method for Heat and Fluid Flow. Wiley, Hoboken, NJ, USA.

Mei VC (1986) Horizontal Ground-coil Heat Exchanger Theoretical and Experimental Analysis. Office of Buildings and Community Systems, US Department of Energy, New York, NY, USA.

Monteith JL (1965) Evaporation and environment. Symposia of the Society for Experimental Biology 19(4): 205-234.

Sanner B, Karytsas C, Mendrinos D and Ryback L (2003) Current status of ground source heat pumps and underground thermal energy storage in Europe. Geothermics 32(1): 579-588, http:// dx.doi.org/10.1016/S0375-6505(03)00060-9.

Sedighi M, Thomas HR and Vardon PJ (2016) Reactive transport of chemicals in unsaturated soils: numerical model development and verification. Canadian Geotechnical Journal 52: 1-11, http://dx.doi.org/10.1139/cgj-2014-0436.

Sverdrup HU (1946) The humidity gradient over the sea surface. Journal of Meteorology 3(1): 1-3.

Thomas HR and He Y (1995) Analysis of coupled heat, moisture and air transfer in a deformable unsaturated soil. Géotechnique 45(4): 677-689, http://dx.doi.org/10.1680/geot. 1995.45.4.677.

Thomas HR, Sedighi M and Vardon PJ (2012) Diffusive reactive transport of multicomponent chemicals under coupled thermal, hydraulic, chemical and mechanical conditions. Geotechnical and Geological Engineering 30(4): 841-857, http://dx.doi.org/ 10.1007/s10706-012-9502-9.

Thomas HR, Hepburn BDP and Sedighi M (2013) Soil thermal behaviour of a horizontal ground source heat system. In Coupled Phenomena in Environmental Geotechnics 
(Manassero M, Dominijanni A, Foti S and Musso G (eds)). CRC, Boca Raton, FL, USA, pp. 525-530.

van Genuchten MT (1980) A closed-form equation for predicting hydraulic conductivity of unsaturated soils. Journal of Soil Society of America 44(1): 892-898.

van Wijk WR (1966) Introduction, the physical method. In Physics of the Plant Environment (van Wijk WR (ed.)). North Holland, Amsterdam, the Netherlands.

van Wijk WR and Scholte Ubing DW (1966) Radiation. In Physics of the Plant Environment (van Wijk WR (ed.)). North Holland, Amsterdam, the Netherlands.

Vardon PJ (2015) Climatic influence on geotechnical infrastructure: a review. Environmental Geotechnics 2(EG3): 166-174, http:// dx.doi.org/10.1680/envgeo.13.00055.

Vardon PJ, Nijssen T, Yao Y and van Tol AF (2014) Numerical simulation of fine oil sand tailings drying in test cells. IOSTC 2014: Proceedings of the 4th International Oil Sands Tailings Conference, Lake Louise, Canada, 7-10 October, pp. 59-69.
Wilson GW, Fredlund DG and Barbour SL (1997) The effect of soil suction on evaporative fluxes from soil surfaces. Canadian Geotechnical Journal 34(1): 145-155, http://dx.doi.org/10. 1139/t96-078.

Woodward SJR, Baker DJ and Zyskowski A (2001) Practical model for predicting soil water deficit in New Zealand pastures. New Zealand Journal of Agricultural Research 44(1): 91-109.

Wu Y, Gan G, Verhoef A et al. (2010) Experimental measurement and numerical simulation of horizontal coupled slinky ground source heat exchanger. Applied Thermal Engineering 30(1): 2574-2583.

Wu Y, Gan G, Gonzalez RG et al. (2011) Prediction of the thermal performance of horizontal-coupled ground-source heat exchangers. International Journal of Low-carbon Technologies 6(1): 261-269.

Yang H, Cui P and Fang Z (2010) Vertical-borehole groundcoupled heat pumps: a review of models and systems. Applied Energy 87(1): 16-27.

\section{How can you contribute?}

To discuss this paper, please submit up to 500 words to the editor at journals@ice.org.uk. Your contribution will be forwarded to the author(s) for a reply and, if considered appropriate by the editorial board, it will be published as a discussion in a future issue of the journal. 